\title{
Safety Evaluation of High Concrete-Faced Rockfill Dam Based on Site-Related Response Spectrum Using Scenario Earthquake
}

\author{
Kai-bin Zhu (D), Hong-jun Li $(\mathbb{D}$, Xiao-gang Wang $(\mathbb{D}$, Xiao-sheng Liu $(\mathbb{D}$, \\ and Jian-ming Zhao
}

China Institute of Water Resources and Hydropower Research, Beijing 100048, China

Correspondence should be addressed to Hong-jun Li; lihj@iwhr.com

Received 16 March 2020; Revised 2 September 2020; Accepted 22 October 2020; Published 9 November 2020

Academic Editor: Andreas Lampropoulos

Copyright ( $\odot 2020$ Kai-bin Zhu et al. This is an open access article distributed under the Creative Commons Attribution License, which permits unrestricted use, distribution, and reproduction in any medium, provided the original work is properly cited.

\begin{abstract}
To clarify how to arrive at earthquake ground motion parameters for use in evaluating the high rockfill dams during seismic loading conditions, as well as to evaluate reasonably the seismic response of dams subjected to strong earthquake, the differences of design response spectra determined by scenario earthquake and uniform hazard spectra theory are investigated in detail. Coupled with the safety evaluation of the Houziyan concrete-faced rockfill dam (CFRD) with a height of $200 \mathrm{~m}$ located in meizoseismal regions, comprehensive comparisons of key safety evaluation indices are performed using input motions determined from the abovementioned two design response spectra. The key safety evaluation indices include dynamic response acceleration, permanent deformation, safety of the impervious body, safety factor, and sliding displacement of the potential failure sliding body. Additionally, the ultimate seismic capability of the high CFRD is discussed based on the two response spectra. More considerable results can be achieved and offered to the engineers for the seismic design. It is obvious that the uniform hazard spectra, which are used to adopt in the safety evaluation of high CFRD, typically result in conservative evaluations and unnecessary economic cost for seismic design and reinforcements.
\end{abstract}

\section{Introduction}

For large-scale hydraulic buildings located in areas with high seismicity, the scientific and reasonable determination of the design response spectrum is directly related to the success or failure of the seismic design and reinforcements. In the past few decades in China, important hydraulic dams with heights above $200 \mathrm{~m}$ - such as Nuozhadu Dam $(262 \mathrm{~m})$, Changheba Dam (240 m), Wudongde Dam (255 m), Lianghekou Dam (293 m), and Shuangjiangkou Dam (314 m) [1] - have all been seismically designed using the uniform hazard spectra based on the probabilistic approach, according to the Chinese regulation [2], the specification for the seismic design of hydraulic structures. Likewise, in the US, the uniform hazard spectrum as a common method for developing design spectra has been used in design practice for the past two decades [3]. However, the "equal probability of exceeding the ground motion at any period" of earthquakes in the UHS is often cited as a disadvantage of engineering applications and theory. Some typical projects have demonstrated that the input motion parameters (e.g., acceleration, characteristic period, and dynamic amplification factor) determined using the UHS are extremely conservative. The $156 \mathrm{~m}$-high Zipingpu concrete-faced rockfill dam (CFRD) suffered only minor damage during the 5.12 Wenchuan earthquake with a peak acceleration of $0.55 \mathrm{~g}$, which was far beyond its designed peak acceleration of $0.26 \mathrm{~g}$ [4]. Similarly, in the seven years between 1979 and 1985, the 148 m-high El Infiernillo Dam suffered four strong earthquakes-even the weakest of the four had a magnitude greater than 7.2-but the maximum permanent displacement was still below $15 \mathrm{~cm} \mathrm{[5].} \mathrm{These} \mathrm{cases,} \mathrm{amongst} \mathrm{others,}$ demonstrate the extreme conservativeness of seismic design and reinforcement measures based on dynamic results obtained from the UHS.

Many scholars have discussed the mechanism of the UHS. The concept of "hazard-consistent" analysis that was proposed by Ishikawa and Kameda [6] was deemed deficient by Wu et al. [7], as it could not reflect the characteristics of a specific earthquake. Similarly, Lan et al. [8] noted that the 
UHS could not reflect the characteristics of ground motion generated by a particular earthquake. Zhang et al. [9] elaborated that the probabilistic method does not define the concepts of magnitude and epicentre distance clearly and cannot be used to evaluate the spectral characteristics of strong earthquakes, the duration of ground motions, or the characteristics of near-faults. Karalar and Çavuşli $[10,11]$ further pointed out the seismic effects of epicentre distance and far fault. The National Earthquake Hazards Reduction Program (NEHRP) Consultants Joint Venture [12] pointed out that the UHS is a conservative target spectrum for seismic analysis and that it is highly unlikely that highamplitude spectral values will be observed during all periods in a single ground motion event. In conclusion, the UHS method is a statistical concept compiled from historical earthquakes for all possible earthquake sources. The essential characteristic of the UHS method is to consider the randomness and uncertainty of an earthquake, with regard to time, space, and earthquake intensity. Therefore, the UHS may lead to conservative results for $200 \mathrm{~m}$-high (heights of around/greater than $200 \mathrm{~m}$ ) rock-filled dams with design accelerations above $0.2 \mathrm{~g}$.

Based on the above analysis, Chen et al. [13] suggested that, to evaluate the safety of important hydraulic structures, a site-related response spectrum-calculated on the basis of a seismic event with clear physical parameters (a "scenario earthquake")-should be adopted rather than the UHS. In China, the newly issued "Code for seismic hydraulic design structures of hydropower project: NB 35047-2015” [14] states that the safety evaluation of hydraulic dams with a height above $150 \mathrm{~m}$ and basic intensity above VII must be conducted based on the site-related response spectrum using the scenario earthquake. However, the specific effect of the input motion parameters-which differ whether based on UHS or site-related response spectrum based on the scenario earthquake-on the dynamic response characteristics of the dam is not clear. In addition, the new code issued in China does not provide clear explanation regarding the determination of ground motion parameters when assessing the ultimate seismic capacity of high rock-filled dams.

Herein, the $223.5 \mathrm{~m}$-high Houziyan Dam is considered as an example of a high CFRD. Several key safety evaluation indices, including response acceleration, permanent deformation, safety of impervious body, safety factor, sliding displacement of potential failure sliding body, and ultimate seismic capacity, are evaluated and compared based on the two input motion parameters determined by UHS and siterelated response spectrum based on the scenario earthquake. In order to clarify the specific effects of the differing input motion parameters on the dynamic response characteristics and provide clear explanations on the determination of ground motion parameters, the paper is structured as follows:

To begin, an explanation of ground motion parameters and how they are determined is given. The analytical method used to determine the dynamic response and the materials used in the construction of the $223.5 \mathrm{~m}$-high Houziyan CFRD are introduced as the analysis foundation of this paper. Subsequently, the seismic response of the high CFRD is evaluated under the designed and more severe ("checked") seismic activity, and the differences in the two response spectra are discussed. This paper describes the ultimate seismic capacity analysis and further evaluates the dam. Finally, the conclusions of the article are given.

\section{Materials and Methods}

2.1. Determination of Input Motion Parameters. Evaluation of the seismotectonics and seismicity of a site is the foundation of seismic hazard analysis. Based on the recognition of the seismotectonics and seismicity of a site $(\geq 150 \mathrm{~km})$ and near-field region $(\geq 25 \mathrm{~km})$, the seismic parameters of a dam site can be obtained through probabilistic seismic hazard analyses.

2.2. The Process of Probabilistic Seismic Hazard Analyses. The UHS is determined by the probabilistic seismic hazard analysis method. Figure 1 illustrates the process of it. The probabilistic analysis considers all sources.

The limitations of the methods are as follows. Probabilistic seismic hazard analysis cannot reflect the characteristics of a specific earthquake; it considers all scenarios with the magnitude and epicentral distance and distribution of all sources.

In most cases, probabilistic seismic hazard analysis is typically used, despite the fact that it inherently results in a conservative target spectrum for seismic analysis. Therefore, it is of utmost importance to identify a new method of determining the seismic parameters.

2.3. Site-Related Response Spectrum Based on Scenario Earthquake Analysis. When comprehensive and accurate regional seismotectonics and seismicity information cannot be acquired, scenario earthquake analysis may be more reasonable than traditional probabilistic seismic hazard analyses. The site-related response spectrum based on scenario earthquake combines the characteristics of deterministic analysis with those of probabilistic analysis.

The site-related response spectrum based on scenario earthquake process can be divided into four key steps:

(1) Based on the probabilistic seismic hazard analysis method, the peak accelerations corresponding to different probabilities of exceedance are obtained

(2) According to the contribution of potential sources to the design acceleration, the most significant potential source is identified

(3) Following the maximum probability rule, the magnitude and epicentral distances of the scenario earthquake under the chosen potential source are determined

(4) The design response spectrum can thus be derived

The essential difference between the UHS and site-related response spectrum based on scenario earthquake is that the UHS method describes the response spectrum of the ground bedrock surface obtained by different periodic 


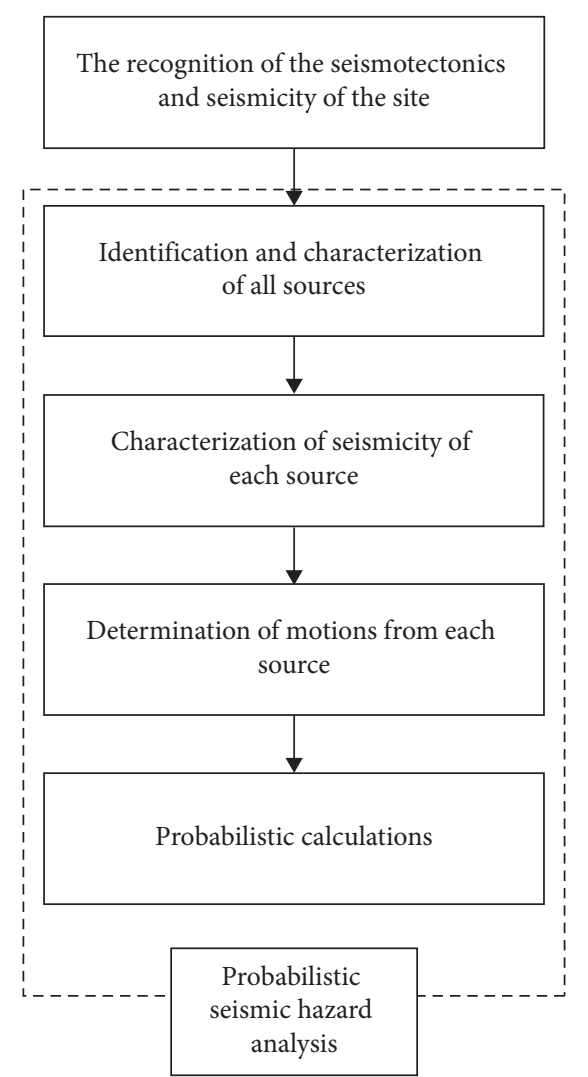

Figure 1: Process of probabilistic seismic hazard analyses.

attenuation rules in seismic safety evaluations and cannot reflect the seismic characteristics of a specific earthquake. On the contrary, the site-related response spectrum based on scenario earthquake is consistent with the characteristics of a specific seismic event, as it is calculated on the basis of a seismic event with clear physical parameters (the scenario earthquake). Notably, this is closely related to the requirements of dam design.

The differences between the UHS and site-related response spectrum based on scenario earthquake have been analysed by researchers. The theoretical and engineering limitations of the UHS have been discussed by the China Institute of Water Resources and Hydropower Research $[13,15]$. Chen et al. [8] pointed out that the short-term component in the UHS is usually controlled by near and small earthquakes, and the long-term component is controlled by distant and large earthquakes, characterizing the UHS with the function of an envelope. The UHS cannot reflect the inherent spectrum characteristics of a strong earthquake that may be encountered at the site, which often makes the response spectrum value in the medium and long periods significantly exaggerated. Hence, it cannot be organically related to physical concepts, such as magnitude and epicentral distance.

2.4. Application and Analysis. Based on the requirements of the newly issued "Code for seismic design of hydraulic structures of hydropower project: NB 35047-2015" in China, the UHS and site-related response spectrum based on scenario earthquake was determined for the $223.5 \mathrm{~m}$-high Houziyan CFRD using the seismic risk analysis methods. For the scenario earthquake analysis, the potential source area numbered 57 (with maximum magnitude 8.0) was selected as the seismogenic structure to produce the siterelated response spectrum based on scenario earthquake. The designed and checked scenario earthquakes, with $2 \%$ and $1 \%$ probability of exceedance in 100 years, respectively, had seismic magnitudes of 8.0 and epicentral distances of 38.0 and $33.0 \mathrm{~km}$, respectively. The magnitudes and distances of the earthquakes were assumed to be substituted into the attenuation relation of AS08 [16], and the acceleration spectra were normalized according to the peak acceleration at bedrock, which is the same as that adopted in the UHS method. The magnification coefficient $\beta(T)$ of different probabilistic levels of the Houziyan Dam site was obtained, and the values of $\beta(T)$ were multiplied by the peak acceleration, corrected by the probabilities of the seismic hazards $\left(1 \%\right.$ in 100 years is $401.0 \mathrm{~cm} / \mathrm{s}^{2} ; 2 \%$ in 100 years is $\left.297.0 \mathrm{~cm} / \mathrm{s}^{2}\right)$. The acceleration response spectra at the bedrock of the Houziyan Dam site have been reported previously $[16,17]$.

Figure 2 illustrates the difference between the UHS and site-related response spectrum based on scenario earthquake at the bedrock of the Houziyan Dam site (as it shown in Table 1). At the same probability level, the UHS (based on safety assessment) is evidently higher than the site-related (SR) response spectrum (based on scenario earthquake analysis), as the period of the SR spectrum (based on scenario earthquake analysis) is below $1.3 \mathrm{~s}$.

According to the abovementioned target response spectrum, transforming the acceleration response spectrum into the power spectrum and amplitude of the time-history accelerations could calculate by the power spectrum. Finally, using trigonometric series superposition method could get acceleration time history. The convergence criteria for obtaining the time-history accelerations is that the relative errors between the synthetic response spectrum of the timehistory accelerations and the target response spectrum is less than $5 \%$.

Figure 3 depicts the time-history input motion (acceleration) parameters in three directions obtained from the UHS and site-related response spectrum based on scenario earthquake of the dam, respectively. In the attached table of the paper, values of the two spectra are listed.

\section{Dynamic Analysis of the Houziyan Concrete- Faced Rockfill Dam (CFRD)}

The Houziyan CFRD is located in the main stream of the Dadu River in Kangding City, Sichuan Province, China. Its crest is $14 \mathrm{~m}$ wide and $223.5 \mathrm{~m}$ high, and the total reservoir capacity is $7.06 \times 10^{8} \mathrm{~m}^{3}$. The gradients of the upstream and downstream slopes are $1: 1.4$ and $1: 1.6$, respectively. The dam is mainly composed of concrete face, rhyolite rockfill, weighted zone, and limestone rockfill. The seismic basic intensity at the site is M 7.0. Based on the seismic risk analysis, the peak acceleration with a $2 \%$ probability of 


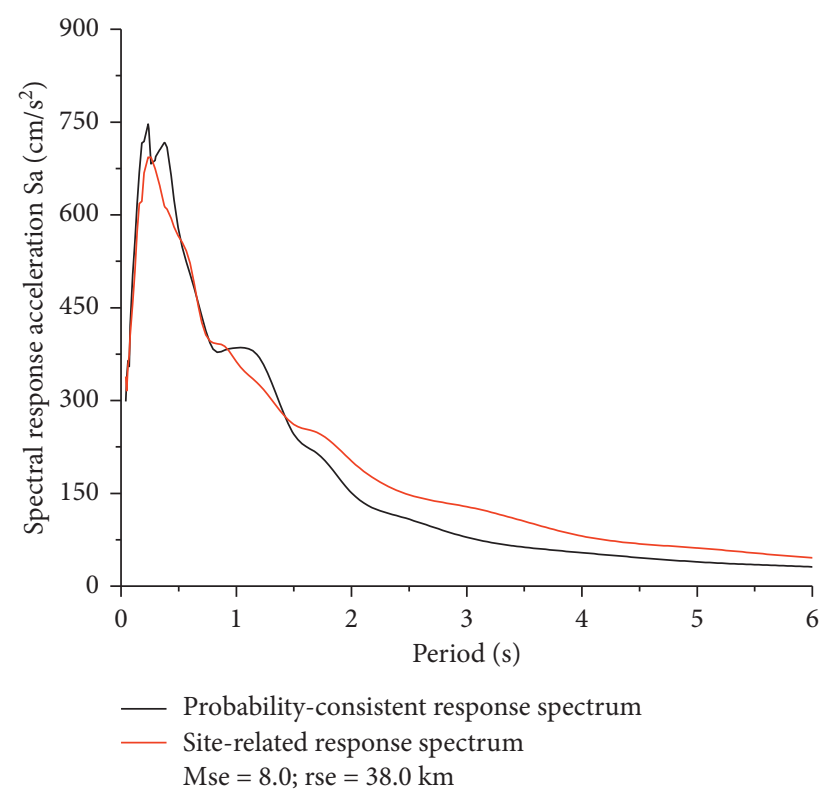

Figure 2: Comparisons of UHS and site-related response spectrum based on scenario earthquake.

TABLE 1: Response spectra shown in Figure 2.

\begin{tabular}{|c|c|c|}
\hline \multirow{2}{*}{ Period, $T$ (s) } & \multicolumn{2}{|c|}{ Acceleration response spectra, $\mathrm{Sa}\left(\mathrm{cm} / \mathrm{s}^{2}\right)$} \\
\hline & UHS & Site-related response spectrum using scenario earthquake \\
\hline 0.04 & 298.4 & 338.6394 \\
\hline 0.05 & 336.5 & 315.8892 \\
\hline 0.06 & 364.4 & 355.9248 \\
\hline 0.07 & 355.1 & 373.1508 \\
\hline 0.08 & 421.7 & 405.2565 \\
\hline 0.10 & 503.8 & 457.1721 \\
\hline 0.12 & 556.5 & 508.0779 \\
\hline 0.14 & 618 & 572.5269 \\
\hline 0.16 & 669.4 & 618.5619 \\
\hline 0.18 & 716.1 & 622.0368 \\
\hline 0.20 & 718.9 & 667.6263 \\
\hline 0.24 & 739.5 & 692.9307 \\
\hline 0.26 & 682.4 & 693.1386 \\
\hline 0.30 & 694 & 671.1309 \\
\hline 0.34 & 706 & 644.2227 \\
\hline 0.38 & 716.5 & 612.6516 \\
\hline 0.40 & 709.1 & 609.1767 \\
\hline 0.46 & 624.4 & 580.635 \\
\hline 0.60 & 504.3 & 522.0369 \\
\hline 0.70 & 436.4 & 426.3138 \\
\hline 0.80 & 382.9 & 393.2577 \\
\hline 0.90 & 381.7 & 387.8523 \\
\hline 1.00 & 385.2 & 362.6073 \\
\hline 1.20 & 369.3 & 325.1259 \\
\hline 1.50 & 245.5 & 261.5085 \\
\hline 1.70 & 214.9 & 248.5593 \\
\hline 2.00 & 150.9 & 202.3758 \\
\hline 2.40 & 113.8 & 154.3212 \\
\hline 3.00 & 78.7 & 128.4822 \\
\hline 3.40 & 65.4 & 110.0979 \\
\hline 4.00 & 54.2 & 81.0513 \\
\hline 5.00 & 39.3 & 61.5978 \\
\hline 6.00 & 31.2 & 45.9162 \\
\hline 7.00 & 22.6 & 38.1645 \\
\hline 8.00 & 16.2 & 24.3837 \\
\hline
\end{tabular}




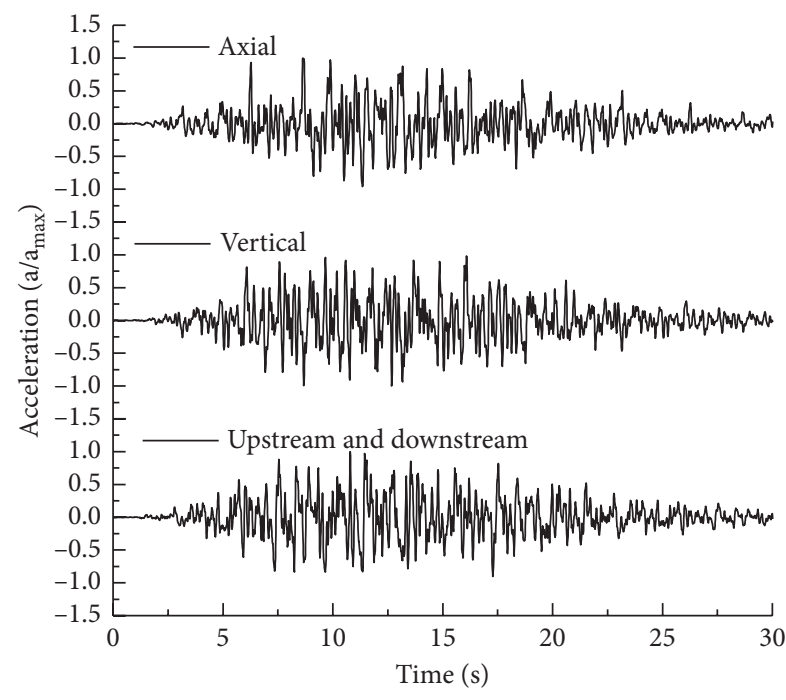

(a)

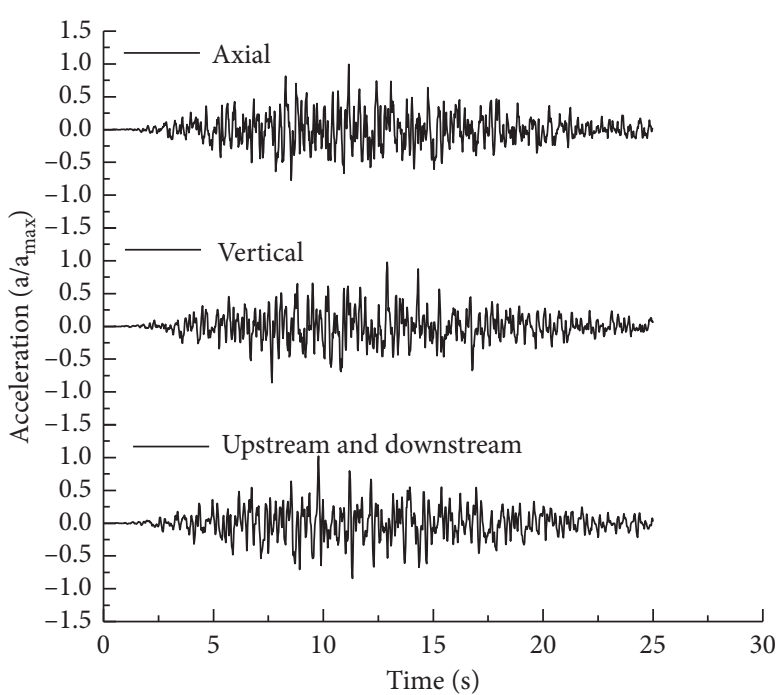

(b)

FIgURE 3: Time-history accelerations of the response spectrum. (a) Time-history accelerations of the site-related response spectrum based on scenario earthquake (SRRS). (b) Time-history accelerations based on UHS.

exceedance is $297 \mathrm{~cm} / \mathrm{s}^{2}$ and that with a $1 \%$ probability of exceedance is $401 \mathrm{~cm} / \mathrm{s}^{2}$.

The input motion (acceleration) parameters based on the seismic risk analyses are plotted in Figure 3. In the calculation, it is assumed that the earthquake lasts for $30 \mathrm{~s}$; the time interval is $0.01 \mathrm{~s}$; the designed maximum acceleration of the earthquake is $297 \mathrm{gal}$; and the boundary adjacent to rock is a fixed boundary. The maximum accelerations in the $X$ (along the stream), $Y$ (vertical), and $Z$ (axial) directions are $2.97,1.98$, and $2.97 \mathrm{~m} / \mathrm{s}^{2}$, respectively. The vertical amplitude of the input motion is two-third of the horizontal amplitude.

Because the concrete face slab is the most important part of the impervious bodies, the dynamic water pressure was equal to be additional mass added to the concrete face slab. Additionally, in this paper, the normal water level of the reservoir $1690 \mathrm{~m}$ was considered during the earthquake for safety.

Considering the basic geology (narrow valley) and ground structure, the model was discretized into a finite element method (FEM) model according to material type. The three-dimensional FEM mesh is depicted in Figure 4. It mainly uses hexahedral elements connected by 8 nodes, and locally uses triprisms and tetrahedral units connected by 6 and 4 nodes, respectively. The peripheral joints and contacts between the slabs and cushions are simulated by contact elements. The FEM model has 29,486 elements and 25,538 nodes in total. The filling of the dam and reservoir impounding was simulated before the dynamic computation. Because the rhyolite rockfill is the main-filled material and it is the hard rock, the particle breakage [18-21] has been ignored.

3.1. Static and Dynamic Parameters. To simulate the dam materials (including cushion material, transition material, main rockfill material, weighted materials, and overburden), the Duncan-Chang nonlinear elastic model was used. This model provides an accurate representation of earth and rock materials and suitably describes the nonlinearity and barotropy of the stress-strain behaviour of soil. The parameters used in the model are listed in Table 2. To simulate the behaviour of the concrete face slab, a linear elastic model was used. The parameters are listed as follows: density $\rho=2.4 \mathrm{~g} /$ $\mathrm{cm}^{3}$; elastic modulus $E=30,000 \mathrm{MPa}$; Poisson ratio $\gamma=0.167$; and dynamic damping ratio $\lambda=0.05$.

The upstream face of the CFRD was set as a type of impervious structure. The interaction between the face slab and cushion layer and the behaviour of the vertical joints between the two face slabs have substantial influence on the stress and deformation behaviour of the face slab. Therefore, dynamic thin layer elements and connecting elements were adopted.

Because of the nonlinearity and hysteretic properties of soil and the evident physical sense of the parameters, the equivalent linearization model is widely used in the earthquake analysis of soil dams for its simplicity and availableness. As a result, there is more engineering experience for the equivalent linearization model than other models. In this model, the maximum dynamic shear modulus $\left(G_{\max }\right)$ can be obtained by equation (1). The dynamic parameters for the five rockfill materials are listed in Table 1. The relationship between the dynamic parameters and amplitude of the shear strain for the five rockfill materials of the dam is presented in Table 3, as obtained from static and dynamic triaxial tests [22]:

$$
G_{\max }=\mathrm{CP}_{a}\left(\frac{\sigma_{0}^{\prime}}{P_{a}}\right)^{n}
$$

where $C$ and $n$ are dynamic parameters, as listed in Table 2; $G_{\max }$ is the average effective stress; and $P_{a}$ is atmospheric pressure. 


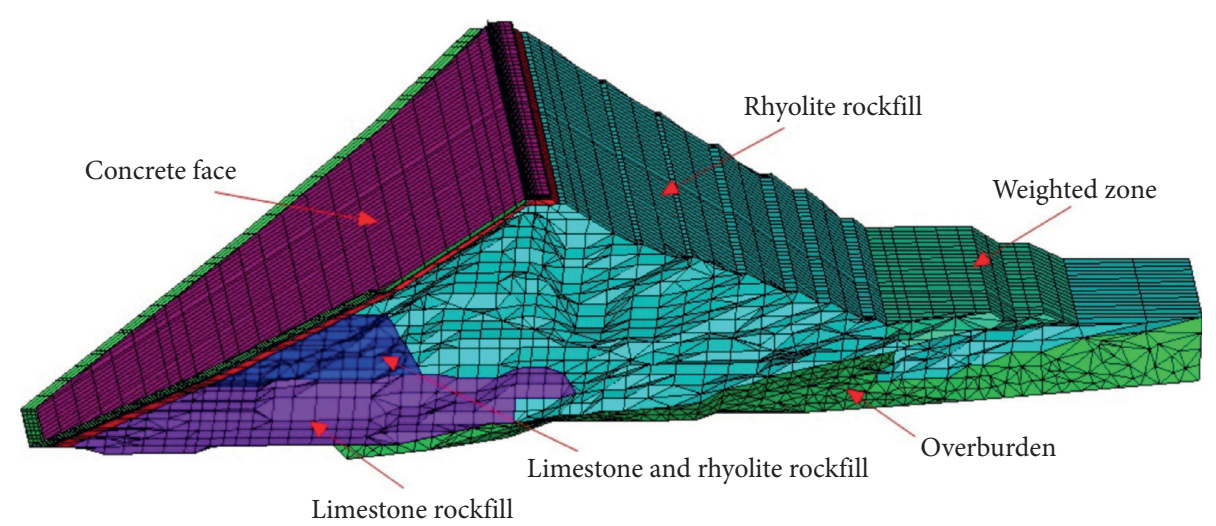

Figure 4: Three-dimensional finite element mesh of the Houziyan Dam.

TABle 2: Static and dynamic parameters of the Houziyan Dam.

\begin{tabular}{|c|c|c|c|c|c|c|c|c|c|c|c|}
\hline \multirow[t]{2}{*}{ Rock-filled material } & \multirow[t]{2}{*}{$\rho\left(\mathrm{g} / \mathrm{cm}^{3}\right)$} & \multirow[t]{2}{*}{$\Phi\left(^{\circ}\right)$} & \multirow[t]{2}{*}{$\Delta \varphi\left(^{\circ}\right)$} & \multirow[t]{2}{*}{$C(\mathrm{kPa})$} & \multicolumn{5}{|c|}{ Duncan-Chang model } & \multicolumn{2}{|c|}{$\begin{array}{c}\text { Equivalent } \\
\text { linear model }\end{array}$} \\
\hline & & & & & $R_{f}$ & $k$ & $n$ & $k_{b}$ & $m$ & C & $n$ \\
\hline Cushion & 2.37 & 50.07 & 5.47 & 0 & 0.77 & 1290 & 0.38 & 489 & 0.33 & 4872 & 0.405 \\
\hline Transition & 2.32 & 49.17 & 6.03 & 0 & 0.79 & 1160 & 0.37 & 424 & 0.30 & 4777 & 0.405 \\
\hline Limestone rockfill & 2.33 & 49.05 & 6.3 & 0 & 0.80 & 1066 & 0.34 & 364 & 0.28 & 4626 & 0.398 \\
\hline Limestone and rhyolite rockfill & 2.33 & 49.05 & 6.3 & 0 & 0.80 & 1066 & 0.34 & 364 & 0.28 & 3106 & 0.468 \\
\hline Rhyolite rockfill & 2.20 & 49.25 & 6.7 & 0 & 0.83 & 1009 & 0.32 & 346 & 0.23 & 1329 & 0.518 \\
\hline
\end{tabular}

$\rho$ is the density of the rockfill material; $c, \varphi$, and $\Delta \varphi$ are parameters of shear strength; $R_{f}, k, n, k_{b}$, and $m$ are parameters of the Duncan-Chang model; $C$ and $n$ are dynamic parameters of the equivalent linear model.

TABLE 3: Ratio of dynamic shear modulus $\left(G / G_{\max }\right)$ and damping $(\lambda)$ at different shear strains $(\gamma)$.

\begin{tabular}{lccccccccc}
\hline Rock-filled material & $\gamma$ & $5 \times 10^{-6}$ & $1 \times 10^{-5}$ & $5 \times 10^{-5}$ & $1 \times 10^{-4}$ & $5 \times 10^{-4}$ & $1 \times 10^{-3}$ & $5 \times 10^{-3}$ & $1 \times 10^{-2}$ \\
\hline \multirow{2}{*}{ Cushion } & $G / G_{\max }$ & 1 & 0.972 & 0.774 & 0.667 & 0.426 & 0.362 & 0.261 & 0.243 \\
& $\lambda$ & 0.0192 & 0.0217 & 0.0292 & 0.0431 & 0.0844 & 0.1092 & 0.1521 & 0.1621 \\
\hline \multirow{2}{*}{ Transition } & $G / G_{\max }$ & 1 & 0.968 & 0.748 & 0.635 & 0.426 & 0.352 & 0.263 & 0.243 \\
& $\lambda$ & 0.0246 & 0.0261 & 0.0321 & 0.0452 & 0.0922 & 0.1162 & 0.1692 & 0.1821 \\
\hline \multirow{2}{*}{ Limestone } & $G / G_{\max }$ & 1 & 0.976 & 0.754 & 0.639 & 0.421 & 0.339 & 0.252 & 0.231 \\
& $\lambda$ & 0.0231 & 0.0236 & 0.0351 & 0.0477 & 0.0921 & 0.1152 & 0.1471 & 0.1522 \\
\hline \multirow{2}{*}{ Limestone and rhyolite } & $G / G_{\max }$ & 1 & 0.979 & 0.7516 & 0.6381 & 0.4195 & 0.3381 & 0.2493 & 0.2295 \\
& $\lambda$ & 0.02352 & 0.02483 & 0.03615 & 0.04932 & 0.09765 & 0.12027 & 0.15073 & 0.15547 \\
\hline \multirow{2}{*}{ Rhyolite } & $G / G_{\max }$ & 1 & 0.986 & 0.746 & 0.636 & 0.416 & 0.336 & 0.243 & 0.226 \\
& $\lambda$ & 0.0245 & 0.0277 & 0.0386 & 0.0531 & 0.1106 & 0.1321 & 0.1592 & 0.1631 \\
\hline
\end{tabular}

Dynamic analyses were then conducted based on the two differing input motions obtained by the UHS and site-related response spectrum based on scenario earthquake.

\subsection{Analytical Method of the Dam Safety Evaluation}

3.2.1. Earthquake-Induced Permanent Deformation. Zhao et al. [23] proposed an equation for the residual volumetric strain by conducting dynamic triaxial tests. The relationships between the residual shear strain $\varepsilon_{d a}$, residual volume strain $\varepsilon_{d V}$, and dynamic shear stress $\Delta \tau$ can be defined by equations (2) and (3).

$$
\begin{gathered}
\varepsilon_{d a}=K_{a}\left(\frac{\Delta \tau}{\sigma_{0}^{\prime}}\right)^{n_{a}}, \\
\varepsilon_{d V}=K_{V}\left(\frac{\Delta \tau}{\sigma_{0}^{\prime}}\right)^{n_{V}},
\end{gathered}
$$

where $\Delta \tau / \sigma_{0}^{\prime}$ is the ratio of dynamic shear stress and $K_{a}, n_{a}$, $K_{V}$, and $n_{V}$ are parameters related to the consolidation ratio, confining compressive stress, dynamic stress, and vibration cycle, respectively. According to the site magnitude, the equivalent number of cycles is 30 . 
3.2.2. Slope Stability and Sliding Displacement. The safety factor for the dam slope and accumulated sliding displacement are determined as follows: the normal and tangential stress ( $\sigma_{n}^{\prime}$ and $\tau_{n}^{\prime}$, respectively), which are located on the sliding surface of the element, can be calculated by the following equations:

$$
\begin{aligned}
& \sigma_{n}^{\prime}=\frac{\sigma_{z}^{\prime}+\sigma_{y}^{\prime}}{2}+\frac{\sigma_{z}^{\prime}-\sigma_{y}^{\prime}}{2} \cos 2 \beta-\tau_{y z} \sin 2 \beta, \\
& \tau_{n}^{\prime}=\frac{\sigma_{z}^{\prime}-\sigma_{y}^{\prime}}{2} \sin 2 \beta+\tau_{y z} \cos 2 \beta,
\end{aligned}
$$

where $\quad \sigma_{z}^{\prime}=\left(\sigma_{z s}^{\prime}+\sigma_{z d}^{\prime}\right), \quad \sigma_{y}^{\prime}=\left(\sigma_{y s}^{\prime}+\sigma_{y d}^{\prime}\right), \quad$ and $\tau_{y z}=\left(\tau_{y z s}+\tau_{y z d}\right) . \sigma_{y s}^{\prime}$ and $\sigma_{y d}^{\prime}$ are the static and dynamic horizontal stresses of the element, respectively. $\sigma_{z s}^{\prime}$ and $\sigma_{z d}^{\prime}$ are the static and dynamic vertical stresses of the element, respectively. $\tau_{y z s}$ and $\tau_{y z d}$ are the static and dynamic shear stresses of the element, respectively. $\beta$ is the angle between the tangential and horizontal sliding surface.

The antislide stability factor $F_{s}$ of the slope is given as follows:

$$
F_{s}=\frac{\sum \sigma_{n i}^{\prime} \tan \varphi_{i}^{\prime} l_{i}+\sum c_{l}^{\prime} l_{i}}{\sum \tau_{n i} l_{i}},
$$

where $\sigma_{n i}^{\prime}$ and $\tau_{n i}$ are the normal and tangential stresses of the sliding surface of element $i$, respectively. $\varphi_{i}^{\prime}$ and $c_{i}^{\prime}$ are the dynamic effective stress indices of the sliding surface of element $i$, respectively. $l_{i}$ is the sliding distance of element $i$.

Considering that $n$ is the position of the failure surface varies with time, which is related to the minimum safety factor, enumeration is a key method for determining the most dangerous slip-circle and thus analysing the sliding deformation. In this manner, the accumulated sliding displacement of the slip-circle corresponding to the minimum safety factor can be determined. For any potential sliding mass, the sliding angular acceleration can be determined by the following equations:

$$
\begin{aligned}
\ddot{\theta}(t) & =\frac{M}{I}, \\
M & =\left(\sum_{i=1}^{n} \tau_{n i} l_{i}-\sum_{i=1}^{n}\left(c_{i}^{\prime}+\sigma_{n i}^{\prime} \tan \varphi^{\prime}\right) l_{i}\right) R,
\end{aligned}
$$

where $I$ is the moment of inertia, $\ddot{\theta}(t)$ is the transient instability sliding angular acceleration, and $M$ is the moment of rotation. The transient sliding displacement $D_{i}^{K}$ and accumulated sliding displacement $D^{K}$ of the slip-circle can be calculated as follows:

$$
\begin{aligned}
& D_{i}^{K}=R^{K} \theta_{i}^{K}=R^{K} \iint \ddot{\theta}_{i}^{K} \mathrm{~d} t, \\
& D^{K}=\sum_{i=1}^{n} D_{i}^{K} .
\end{aligned}
$$

\section{Results and Discussion}

\subsection{Regular Seismic Capacity Analysis}

4.1.1. Maximum Response Acceleration. With respect to Figure 5, under UHS seismic conditions, the biggest dynamic response in the downstream directional acceleration occurs at the crest of the dam and is approximately $8.44 \mathrm{~m} /$ $\mathrm{s}^{2}$. The maximum magnifications of acceleration (response acceleration/input acceleration) in the vertical and axial directions of the dam are 3.24 and 2.6, respectively. However, when calculated under site-related response spectrum based on scenario earthquake seismic conditions, the maximum acceleration in the downstream direction is approximately $7.72 \mathrm{~m} / \mathrm{s}^{2}$, and the magnifications in the three directions are 2.60 (along the stream), 2.64 (vertical), and 2.39 (axial). In considering the influence of the differences in these spectra, it is worth noting that the maximum accelerations in the downstream direction are all located at the top of the dam, and that the amplification is consistent with the difference between the two response spectra, as shown in Figure 2.

In terms of the maximum response acceleration, the major differences between the two types of spectra are reflected in the vertical direction. When using the UHS, the distribution of vertical acceleration is largest approximately four-fifths up the height of the dam at the downstream slope and is consistent with that at the top of the dam; however, when using the site-related response spectrum based on scenario earthquake, the largest acceleration is located at the upstream slope approximately four-fifths up the height of the dam, as shown in Figure 6.

In evaluating the seismic response of the Houziyan Dam, we find that the response acceleration increases with dam height, and the acceleration whiplash effect is the largest at the top of the dam. Furthermore, the magnification of the three-directional acceleration and distribution of vertical acceleration could reflect the difference between the two types of response spectra.

4.1.2. Permanent Deformation. The permanent deformation features of the Houziyan Dam are outlined in Figures 7 and 8. The distribution and tendency of permanent deformation are similar under the different spectra in all directions. The maximum permanent deformation caused by seismic activity is observed at the top of the dam. Permanent settlement (subsidence of the top of the dam) is concentrated at the crest of the dam, which indicates that reinforcement measures should be considered at the upper part of the Houziyan Dam. The contour lines of horizontal permanent displacement illustrate a potential slip surface in the dam upon the occurrence of a strong earthquake.

The amplitude of permanent deformation is reduced by $20 \%$ when calculated using the site-related response spectrum based on scenario earthquake rather than the UHS, as listed in Table 4; for instance, the maximum settlement suggested by the site-related response spectrum based on 


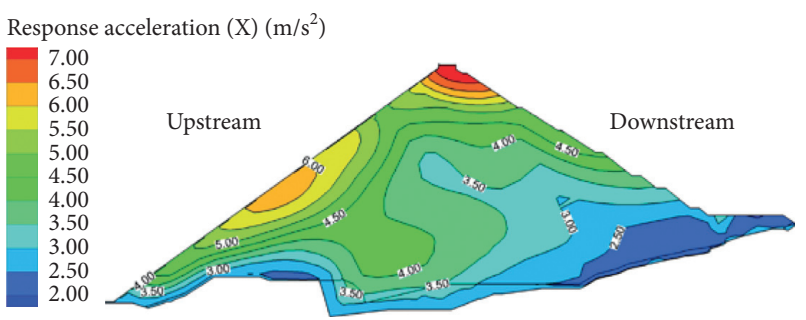

(a)

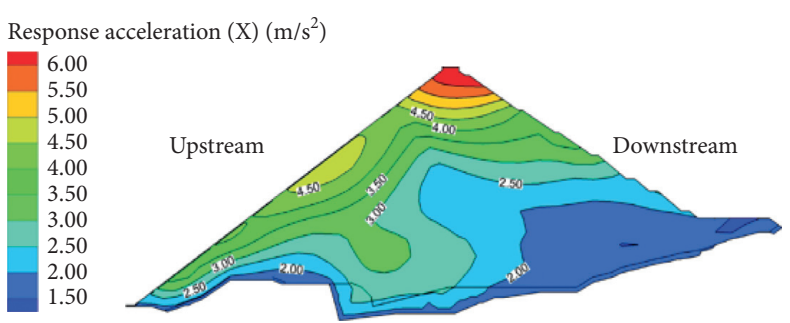

(b)

FiguRE 5: Distribution of response acceleration in the up-downstream direction $\left(\mathrm{m} / \mathrm{s}^{2}\right)$. (a) The distribution of response acceleration based on UHS. (b) The distribution of response acceleration based on site-related response spectrum using scenario earthquake (SRRS).



(a)

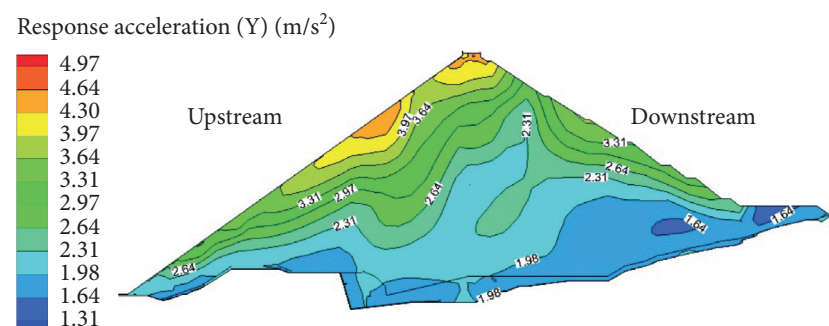

(b)

FIGURE 6: Distribution of response acceleration in the vertical direction $\left(\mathrm{m} / \mathrm{s}^{2}\right)$. (a) The distribution of response acceleration based on UHS. (b) The distribution of response acceleration based on site-related response spectrum using scenario earthquake (SRRS).



(a)



(c)

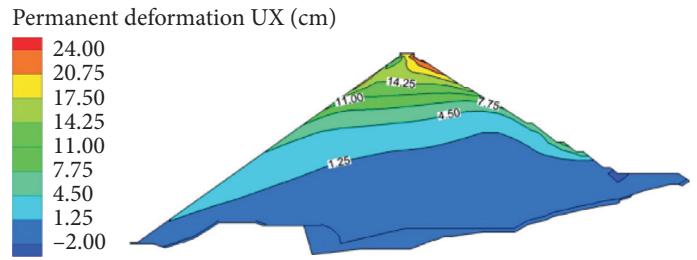

(b)

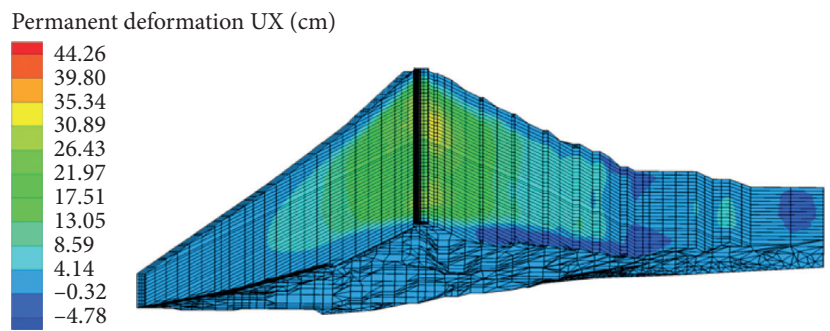

(d)

Figure 7: Permanent deformation in the up-downstream direction (cm). (a) A 2D view image of the distribution of permanent deformation based on UHS. (b) A 2D view image of the distribution of permanent deformation based on site-related response spectrum using scenario earthquake (SRRS). (c) A 3D view image of the distribution of permanent deformation based on UHS. (d) A 3D view image of the distribution of permanent deformation based on site-related response spectrum using scenario earthquake (SRRS).

scenario earthquake is $91.36 \mathrm{~cm}$, which is much lower than that the using the UHS $(112.63 \mathrm{~cm})$. Owing to the development of advanced construction technology, the density of rockfill material is higher than that with conventional construction technology; therefore, earthquake-induced damage should be reduced to some extent. Thus, the permanent deformation obtained by the site-related response spectrum based on scenario earthquake might be more reasonable.

4.1.3. Dynamic Slope Stability. Figure 9 shows how the safety factor changes over time. Notably, the safety factor momentarily falls below the minimum safety control level of 1.0 several times during the design ground motions obtained 


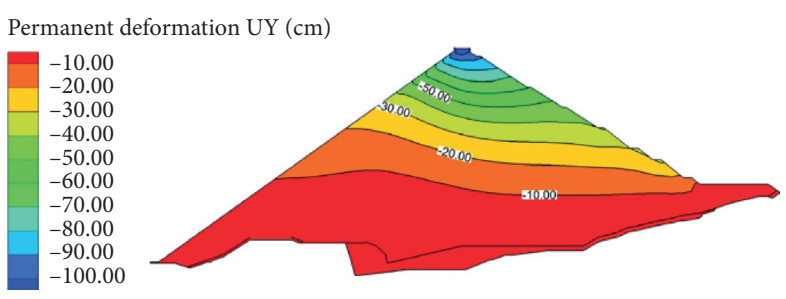

(a)

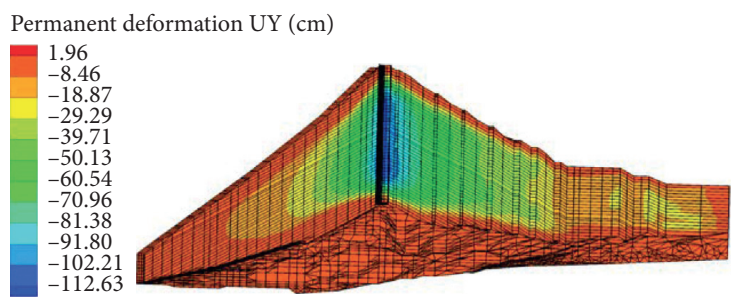

(c)

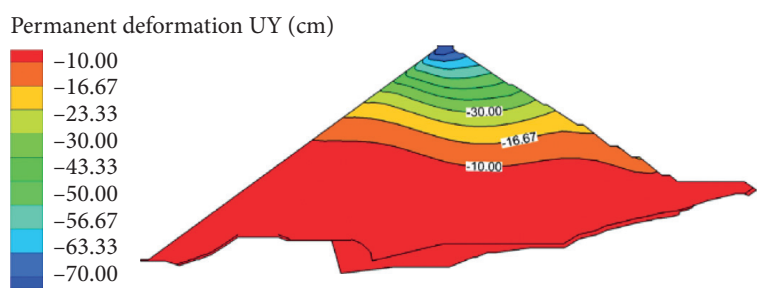

(b)

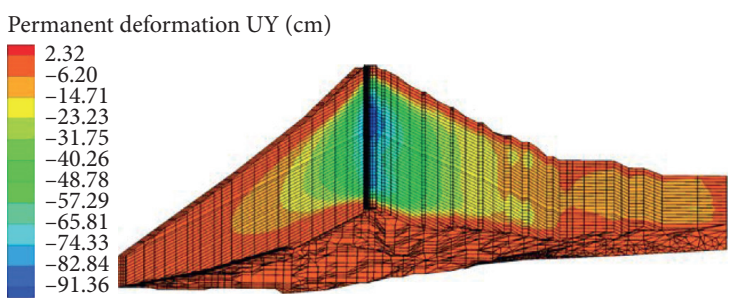

(d)

Figure 8: Permanent deformation in the vertical direction (cm). (a) A 2D view image of the distribution of permanent deformation based on UHS. (b) A 2D view image of the distribution of permanent deformation based on site-related response spectrum using scenario earthquake (SRRS). (c) A 3D view image of the distribution of permanent deformation based on UHS. (d) A 3D view image of the distribution of permanent deformation based on site-related response spectrum using scenario earthquake (SRRS).

TABLE 4: Dynamic response analyses of the Houziyan high concrete-faced rockfill dam.



*Evaluated based on the site-related response spectrum based on scenario earthquake; ${ }^{\dagger}$ evaluated based on the UHS; ${ }^{*}$ the duration(s) for which the safety factor (Fs) was below 1.0.

from both UHS and site-related response spectrum based on scenario earthquake. When using the UHS, the accumulated instability duration is $0.69 \mathrm{~s}$, which is approximately 2.6 times larger than the result obtained from the site-related response spectrum based on scenario earthquake.

The graphs of sliding displacement are presented in Figure 10. When evaluated using the UHS, the maximum cumulative sliding displacement of the sliding surfaces in the downstream slope is $17.9 \mathrm{~cm}$. However, the maximum sliding displacement based on the site-related response spectrum using scenario earthquake is only one-third of this value. The presentation of the most dangerous sliding surfaces in Figure 11 can be mapped to determine the permanent deformation in the downstream direction of the dam slope. Analysis of the most dangerous sliding surfaces further indicated the location of the potential slip surface, demonstrating the necessity of reinforcement measures at the upper part of the Houziyan Dam. From the perspectives of dynamic slope stability, the UHS might lead to conservative results.

4.1.4. Seismic Safety Control of Impervious Bodies. The impervious body consists of the concrete face, vertical joints, peripheral joints, and horizontal construction joint. Contour maps of the maximum tensile and compressive stress are shown in Figure 12. The tensile stress is concentrated in the region close to the bedrock. Using the site-related response 


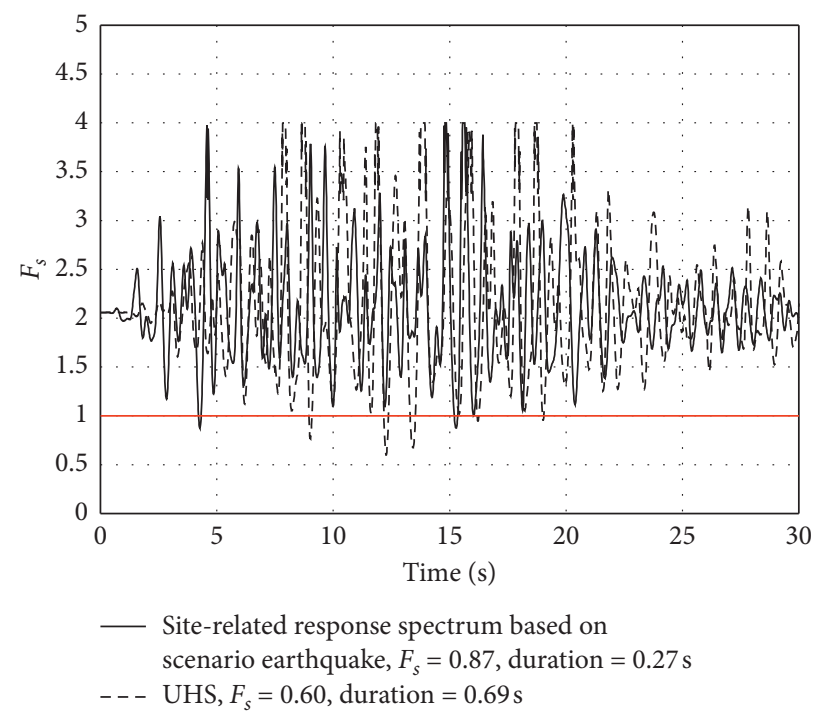

Figure 9: Minimum downstream slope safety factor (Fs) with time using different response spectra.



Figure 10: Sliding displacement with time in the downstream dam slope.

spectrum based on scenario earthquake, the maximum tensile stress is located four-fifth up the height of the face slab, with values of $0.62 \mathrm{MPa}$ along the slope and $1.18 \mathrm{MPa}$ axially around the dam. The distribution is extremely similar when using the UHS. According to the site-related response spectrum based on scenario earthquake, the maximum compressive stress is $14.34 \mathrm{MPa}$ along the slope towards the face slab direction (representing the top part of the panel) and $11.35 \mathrm{MPa}$ along the axial direction (representing half of the height of the dam); these values are approximately 5-10\% lower than the results using UHS analysis.

Table 5 shows the stress distribution of the concrete slab and displacement of the vertical joints, peripheral joints, and horizontal construction joint under the designed ground motions. The maximum displacement of the joints is within the permissible value of displacement. The stress distribution of the concrete face and displacement of the joints determined using the site-related response spectrum based on scenario earthquake are evidently lower than those determined using UHS. Therefore, based on the above analysis of the seismic safety control of impervious bodies, the distribution of panel stresses predicted by the UHS is similar to that predicted by the site-related response spectrum based on scenario earthquake, and both satisfy the design requirements. However, the results also reinforce the view that the site-related response spectrum based on scenario earthquake has an adequate safety margin in the case of the dam being subjected to strong earthquake attack.

For comparative analysis, Tables 4 and 5 summarize the main dynamic analysis results of the Houziyan Dam under different ground motion designs. The safety evaluation results under the designed and checked ground motions based 


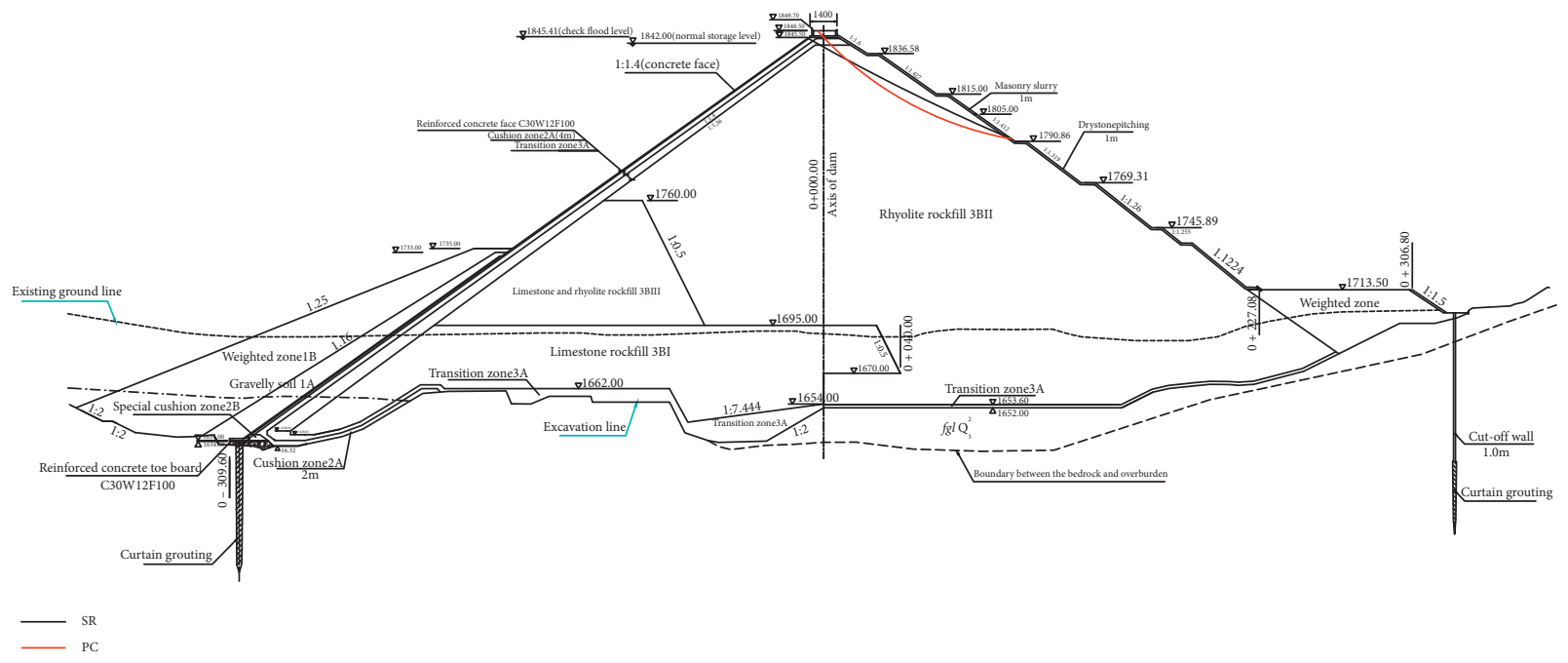

FIgURE 11: Most dangerous sliding surfaces in the downstream dam slopes.

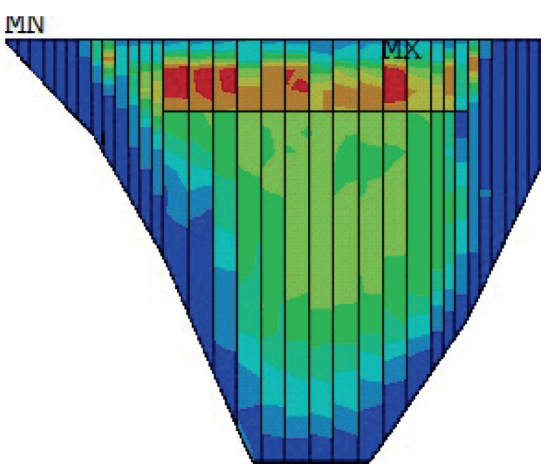

(a)

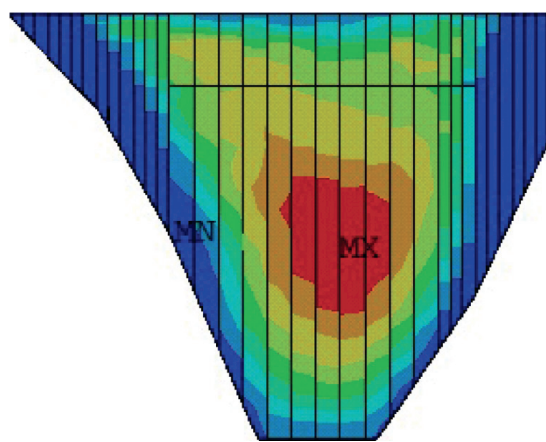

(c)

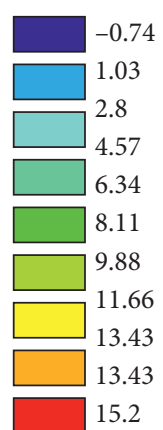

15.2

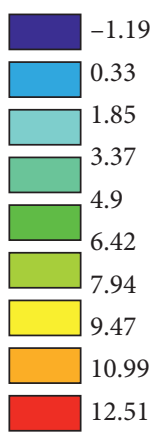

12.51
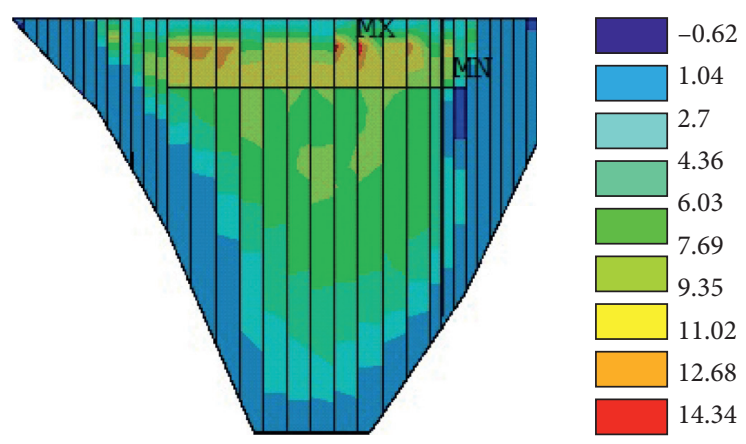

(b)


(d)

FIGURE 12: Stress distribution of concrete slab after earthquake. (a) The stress distribution of concrete slab in the along-slope direction based on UHS along-slope (UHS). (b) The stress distribution of concrete slab in the along-slope direction based on site-related response spectrum using scenario earthquake (SRRS) along-slope (SRRS). (c) The stress distribution of concrete slab in the axial direction based on UHS axial (UHS). (d) The stress distribution of concrete slab in the axial direction based on site-related response spectrum using scenario earthquake (SRRS) axial (SRRS).

on the site-related response spectrum using scenario earthquake suggest evidently superior performance of the dam with regard to dynamic response acceleration, permanent deformation, safety of impervious body, safety factor, and sliding displacement of the potential failure surfaces than those based on the UHS. This is because the natural vibration period of the high earth-rock structure of the Houziyan Dam is within 1.0-1.5 s. The magnification of spectral acceleration is evidently higher under the UHS than under the site-related response spectrum based on scenario 
TABLE 5: Seismic safety of impervious body.

\begin{tabular}{|c|c|c|c|c|c|}
\hline & & Designed & & Checked & \\
\hline Seismic parameters & & $\begin{array}{c}\text { Site-related response } \\
\text { spectrum based on scenario } \\
\text { earthquake* }\end{array}$ & $\mathrm{UHS}^{\dagger}$ & $\begin{array}{c}\text { Site-related response } \\
\text { spectrum based on scenario } \\
\text { earthquake* }^{*}\end{array}$ & $\mathrm{UHS}^{\dagger}$ \\
\hline Along & $\begin{array}{c}\text { Dynamic } \\
\text { compression } \\
\text { stress }\end{array}$ & 13.76 & 13.97 & 17.59 & 21.34 \\
\hline Stress distribution of & $\begin{array}{c}\text { Dynamic tensile } \\
\text { stress }\end{array}$ & 10.70 & 14.15 & 15.89 & 21.42 \\
\hline $\begin{array}{l}\text { concrete slab under the } \\
\text { ground motion (MPa) }\end{array}$ & $\begin{array}{l}\text { Dynamic } \\
\text { compression } \\
\text { stress }\end{array}$ & 4.58 & 5.81 & 6.72 & 7.20 \\
\hline & $\begin{array}{c}\text { Dynamic tensile } \\
\text { stress }\end{array}$ & 4.58 & 5.97 & 6.16 & 8.28 \\
\hline Along & $\begin{array}{c}\text { Compression } \\
\text { stress }\end{array}$ & 14.65 & 15.20 & 16.58 & 18.11 \\
\hline $\begin{array}{ll}\text { Stress distribution of } & \text { the slope } \\
\text { concrete slab after earthquake } & \end{array}$ & Tensile stress & 0.62 & 0.74 & 0.75 & 0.76 \\
\hline $\begin{array}{l}\text { concrete slab arter earthquake } \\
(\mathrm{MPa})\end{array}$ & $\begin{array}{l}\text { Compression } \\
\text { stress }\end{array}$ & 11.35 & 12.51 & 12.05 & 13.09 \\
\hline & Tensile stress & 1.18 & 1.19 & 1.18 & 1.37 \\
\hline & Shear & 32 & 36 & 41 & 46 \\
\hline $\begin{array}{l}\text { Maximum displacement of peripheral } \\
\text { ioint after earthoule }(\mathrm{mm})\end{array}$ & Subsidence & 30 & 33 & 36 & 43 \\
\hline & Stretch & 26 & 31 & 33 & 33 \\
\hline & Shear & 29 & 32 & 40 & 44 \\
\hline $\begin{array}{l}\text { Maximum displacement of vertical joint } \\
\text { after earthauake (mm) }\end{array}$ & Subsidence & 37 & 39 & 42 & 43 \\
\hline & Stretch & 32 & 35 & 40 & 41 \\
\hline & Shear & 11 & 15 & 13 & 17 \\
\hline Maximum displacement of horizontal & Subsidence & 9 & 12 & 9 & 15 \\
\hline construction joint after earthquake (mm) & Stretch & 9 & 13 & 11 & 16 \\
\hline
\end{tabular}

${ }^{*}$ Evaluated based on the site-related response spectrum based on scenario earthquake. ${ }^{\dagger}$ Evaluated based on the UHS.

earthquake within this period, as shown in Figure 2. For the Houziyan Dam, it is easy to obtain conservative results in seismic safety evaluations based on UHS.

4.2. Ultimate Seismic Capacity Analysis. Based on the above results, the peak acceleration was adjusted to $0.50,0.55$, and $0.60 \mathrm{~g}$, using acceleration-time curves based on the UHS and site-related response spectrum based on scenario earthquake. The ultimate seismic capacity of the Houziyan CFRD was studied by core evaluation indices such as the stability of slopes, permanent deformation of the dam, and impervious body safety [24-26]. Furthermore, the influence of the selection of design response spectrum on the analysis of ultimate seismic capacity was further clarified. The main calculation results are summarized in Table 6.

4.2.1. Safety Control of Downstream Slope Stability. Using the UHS, when the peak acceleration of the input is $0.401 \mathrm{~g}$, the minimum safety factor of the downstream slope is 0.35 , which is considerably less than the safety control limit of 1.0, and the accumulated sliding displacement of the most dangerous slip arc is $0.62 \mathrm{~m}$. The accumulated duration at which the safety factor is below 1.0 is $1.54 \mathrm{~s}$, as shown in Figure 13. The accumulated plastic sliding displacement is less than $1.2 \mathrm{~m}$ when the accumulated duration exceeds the safety control limit of $1.0 \mathrm{~s}$. However, the integral and local safety of the dam slope is difficult to guarantee. With regard to downstream slope stability, the ultimate seismic capacity of the dam based on the UHS is $0.297-0.401 \mathrm{~g}$.

The site-related response spectrum based on scenario earthquake produces differing results. Under an acceleration of $0.55 \mathrm{~g}$, the minimum safety factor of the downstream slopes is 0.42 when using the site-related response spectrum based on scenario earthquake, and the accumulated sliding displacement of the most dangerous slip arc is $0.66 \mathrm{~m}$. Notably, the accumulated duration at which the safety factor is below 1.0 is less than $1.0 \mathrm{~s}$, with seismic slip of the downstream slope of less than $1.2 \mathrm{~m}$. The ultimate seismic capacity of the dam based on site-related response spectrum using scenario earthquake is $0.55-0.60 \mathrm{~g}$.

4.2.2. Safety Control of Permanent Deformation. Using the ground motion described by the UHS, when the peak acceleration is $0.50 \mathrm{~g}$, the maximum vertical residual deformation (seismic settlement) of the dam is predicted to be $2.02 \mathrm{~m}$, which is $0.91 \%$ of the dam height; this settlement is expected to occur at the top of the dam. The seismic settlement rate $(0.91 \%)$ exceeds the safety control range of $0.6-0.8 \%$ as shown in Figure 14; this suggests the dam will suffer evident earthquake damage. With regard to permanent deformation, the ultimate seismic capacity of the dam based on the UHS is $0.401-0.50 \mathrm{~g}$. 
TABLE 6: Ultimate seismic capability of the high concrete-faced rockfill dam.

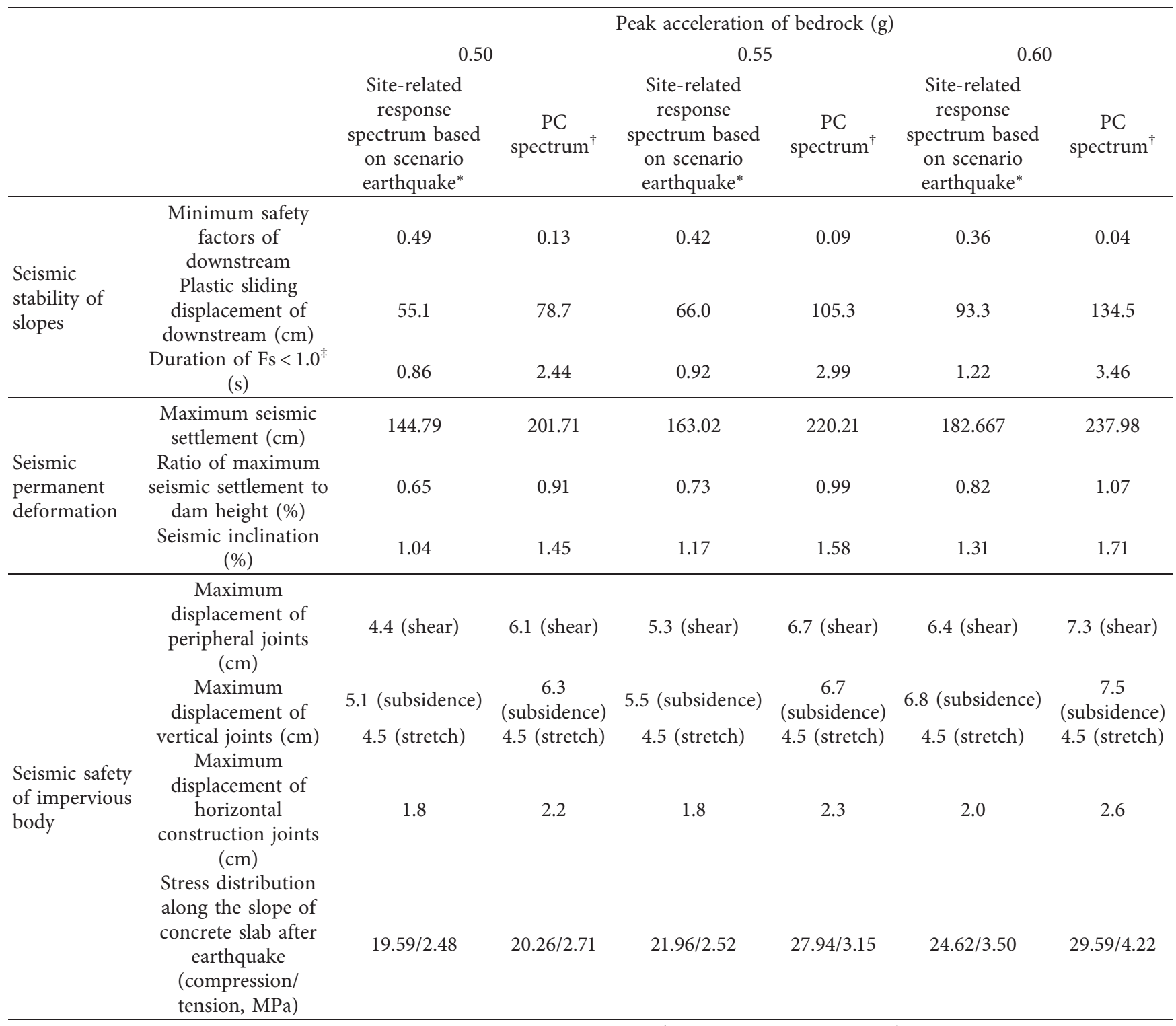

*Evaluated based on the site-related response spectrum based on scenario earthquake. ${ }^{\dagger}$ Evaluated based on the UHS. ${ }^{*}$ The duration(s) for which the safety factor (Fs) was below 1.0.

Using the site-related response spectrum based on scenario earthquake, when the peak acceleration is $0.60 \mathrm{~g}$, the maximum seismic settlement of the dam is predicted to be $1.83 \mathrm{~m}(0.82 \%$ of the dam height), and the seismic inclination is $1.31 \%$ (Table 6). Hence, the ultimate seismic capacity of the dam based on the site-related response spectrum using scenario earthquake is $0.55-0.60 \mathrm{~g}$.

4.2.3. Seismic Safety Control of Element and Impervious Body. Using the ground motion from the UHS, when the peak acceleration is $0.50 \mathrm{~g}$, there are areas of serious dynamic shear failures upon the downstream slopes and at the top of dam which are consistent with the time-history analyses of slope stability; the entirety of instability and sliding of the slopes is expected to be caused by these large areas of shear failure. Furthermore, the maximum displacements of the peripheral and vertical joints exceed the design values (the limit for the shearing displacement of peripheral joints is $6.0 \mathrm{~cm}$; and that for the shearing and stretching displacements of peripheral joints are 5.0 and $6.0 \mathrm{~cm}$, respectively). Therefore, with regard to the safety of the elements and the impervious body, the ultimate seismic capacity of the dam based on UHS is $0.40-0.50 \mathrm{~g}$.

When using the ground motion from the site-related response spectrum based on scenario earthquake with the same peak acceleration $(0.50 \mathrm{~g})$, there are a few elements with a seismic safety factor below 1.0 located in the downstream of dam shell surface as shown in Figure 15; however, no penetrating failure is expected. Nevertheless, increasing the peak acceleration to $0.60 \mathrm{~g}$ increases the maximum displacements of the peripheral and vertical joints 


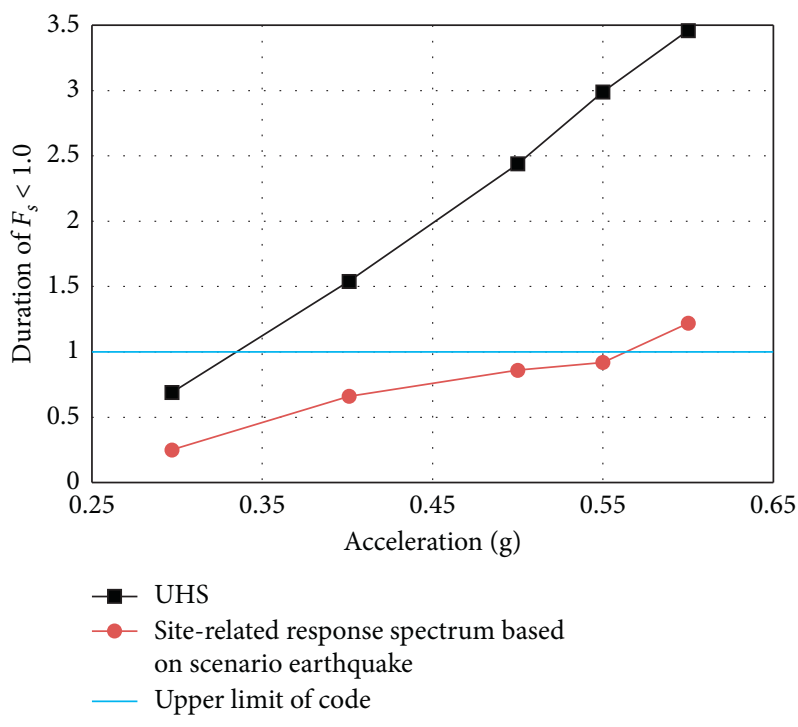

FIgURE 13: Duration for which the safety factor Fs is below 1.0 using different response spectra.

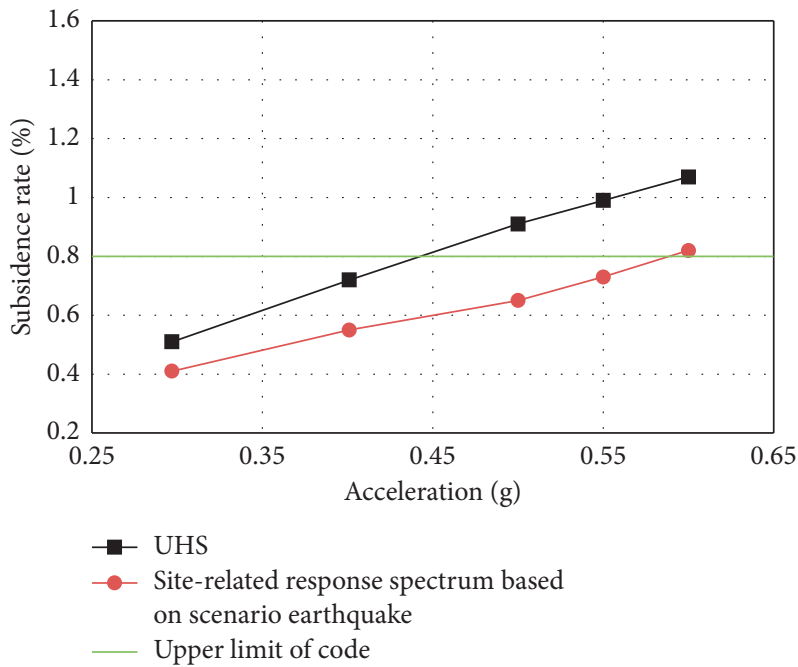

FIGURE 14: Earthquake-induced settlement with acceleration using different response spectra.



(a)

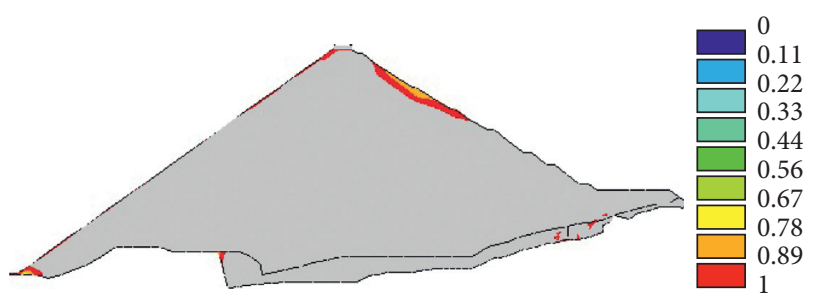

(b)

FIGURE 15: Distribution of safety factor below 1.0 ( $0.50 \mathrm{~g}$ of soil elements (SRRS). (a) UHS. (b) SRRS. 
above the aforementioned design values. The ultimate seismic capacity of the dam based on the site-related response spectrum based on scenario earthquake is $0.55 \mathrm{~g}$.

\section{Conclusions}

The differences of the results of safety evaluations of high rockfill dams subjected to strong earthquakes based on UHS and site-related response spectrum based on scenario earthquake were discussed in detail taking the Houziyan CFRD for example. The key safety evaluation indices under the two types of response spectra were studied, including the acceleration of dynamic response acceleration, permanent deformation, stability of dam slopes, safety of impervious body, and ultimate seismic capacity. The specific conclusions are as follows:

(1) Taking the typical Houziyan CFRD as an example, based on the major safety evaluations indices, the UHS could generate more conservative evaluation results.

(2) The ultimate seismic capacity of the Houziyan CFRD, which was determined by the slope stability, seismic settlement, and safety of the impervious body, was evidently higher when using the site-related response spectrum based on scenario earthquake than the UHS. From the point of view, CFRD projects designed based on the traditional UHS might tolerate strong earthquakes with magnitudes far above the maximum credible earthquakes, such as Zipingpu CFRD dam.

(3) For high CFRD projects, especially those located in areas at a risk of strong earthquakes, seismic safety evaluations and ultimate seismic capacity analyses could be considered using seismic parameters determined from the site-related response spectrum based on scenario earthquake analysis. Hence, economically favourable and reasonable seismic design and available reinforcement measures can be implemented by the engineers.

\section{Data Availability}

The data (Tables 1-3) used to support the findings of this study are included within the article.

\section{Conflicts of Interest}

The authors declare that there are no conflicts of interest regarding the publication of this paper.

\section{Acknowledgments}

This study was supported by all members of the scientific research team belonging to the Soil Dynamic Department of the Institute of Geotechnical Engineering Department of China Institute of Water Resources and Hydropower Research. The authors hereby thank Qi-wang Liu for providing the technical guidance of test data processing and Zhengquan Yang and Yu-sheng Yang for providing the project information. This research was funded by the National Key Research and Development Program of China (grant number: 2017YFCC0404904); the National Nature Science Foundation of China (grant number: 51579033); and IWHR Research and Development Support Program (grant number: GE0145B562017).

\section{References}

[1] L.-Y. Liu and L.-P. Wen, "Analysis on high dam large reservoir statistics in China," Water Conservancy Construction and Management, vol. 36, pp. 12-16, 2016, in Chinese.

[2] China Institute of Water Resources and Hydropower Research, Specifications for Seismic Design of Hydraulic Structures. DL 5073-2000, China Electric Power Press, Beijing, China, 2001, in Chinese.

[3] National Earthquake Hazards Reduction Program (NEHRP) Consultants Joint Venture and Partnership of the Applied Technology Council and Consortium of Universities for Research in Earthquake Engineering, Comparison of U.S. and Chilean Building Code Requirements and Seismic Design Practice 1985-2010, National Institute of Standards and Technology, Gaithersburg, MD, USA, 2012.

[4] X.-J. Kong, Y. Zhou, D.-G. Zou, and B. Xu, "Study of seismic wave input of Zipingpu concrete face rockfill dam during Wenchuan earthquake," Rock and Soil Mechanics, vol. 33, pp. 2110-2116, 2012, in Chinese.

[5] A.-W. M. Elgamal and R. V. Gunturi, "Dynamic behaviour and seismic response of El Infiernillo dam," Earthquake Engineering \& Structural Dynamics, vol. 22, no. 8, pp. 665$684,1993$.

[6] Y. Ishikawa and H. Kameda, "Hazard-consistent magnitude and distance for extended seismic risk analysis," in Proceedings of the 9th World Conference on Earthquake Engineering, vol. 11, pp. 89-94, Tokyo-Kyoto, Japan, August-1988.

[7] J. Wu, The Study on Determination Method of Scenario Earthquake, Institute of Geophysics, China Earthquake Administration, Beijing, China, 2013.

[8] H.-Q. Chen, M. Li, and Y.-C. Shi, "Determination of design response spectrum for important structures based on scenario earthquake," Journal of Hydraulic Engineering, vol. 12, pp. 1399-1400, 2005, in Chinese.

[9] C.-R. Zhang, H.-Q. Chen, D.-Y. Li, and M. Li, "Determination of design response spectrum for important structures based on scenario earthquake," Hydropower Pumped Storage, vol. 4, pp. 56-61, 2018, in Chinese.

[10] M. Karalar and M. Çavuşli, "Seismic effects of epicenter distance of earthquake on 3D damage performance of CG dam," Earthquakes and Structures, vol. 18, no. 2, pp. 201-213, 2020.

[11] M. Karalar and M. Çavuşli, "Evaluation of 3D nonlinear earthquake behaviour of ilisu CFR dam under far fault ground motions," Advances in Civil Engineering, vol. 2019, Article ID 7358710, 15 pages, 2019.

[12] NEHRP Consultants Joint Venture and Partnership of the Applied Technology Council and Consortium of Universities for Research in Earthquake Engineering, Selecting and Scaling Earthquake Ground Motions for Performing Response-History Analyses, National Institute of standards and technology, Gaithersburg, MD, USA, 2011.

[13] H.-L. Lan, L.-P. Xu, and Y.-G. Cui, "Discuss of method to determine consistent spectra decaying constant," Technology for Earthquake Disaster Prevention, vol. 3, pp. 335-339, 2009, in Chinese. 
[14] National Energy Administration, Code for Seismic Design of Hydraulic Structures of Hydropower Project: NB 35047-2015, China Electric Power Press, Beijing, China, 2015, in Chinese.

[15] H.-Q. Chen, M. Li, and Y.-H. Zhang, "Earthquake-resistant analysis on high arch dam and study on the dynamic stability of dam abutment," Water Power, vol. 08, pp. 48-50, 2001, in Chinese.

[16] China Institute of Water Resources and Hydropower Research, Research on the Site-Related Response Spectrum of Houziyan Dam in Sichuan Province, China Institute of Water Resources and Hydropower Research, Beijing, China, 2016, in Chinese.

[17] China Institute of Water Resources and Hydropower Research, Seismic Safety Evaluation of Houziyan Dam under Site Related Seismic and Reservoir-Induced Earthquake, China Institute of Water Resources and Hydropower Research, Beijing, China, 2006, in Chinese.

[18] P. V. Lade, J. A. Yamamuro, and P. A. Bopp, "Significance of particle crushing in granular materials," Journal of Geotechnical Engineering, vol. 122, no. 4, pp. 309-316, 1996.

[19] Y. Xiao and H. Liu, "Elastoplastic constitutive model for rockfill materials considering particle breakage," International Journal of Geomechanics, vol. 17, no. 1, Article ID 04016041, 2017.

[20] Y. Xiao, M. Meng, A. Daouadji, Q. Chen, Z. Wu, and X. Jiang, "Effects of particle size on crushing and deformation behaviors of rockfill materials," Geoscience Frontiers, vol. 11, no. 2, pp. 375-388, 2020.

[21] Y. Xiao, Z. Sun, A. W. Stuedlein, C. Wang, Z. Wu, and Z. Zhang, "Bounding surface plasticity model for stress-strain and grain-crushing behaviors of rockfill materials," Geoscience Frontiers, vol. 11, no. 2, pp. 495-510, 2020.

[22] China Institute of Water Resources and Hydropower Research, Research on the Dynamic Test of the Material Used in Houziyan Dam, China Institute of Water Resources and Hydropower Research, Beijing, China, 2014, in Chinese.

[23] J.-M. Zhao, N. Chen, Y.-P. Chang, and Y.-L. Liu, "Study on earthquake-induced permanent deformation of Longshou CFRD," World Earthquake Engineering, vol. 19, pp. 57-62, 2003, in Chinese.

[24] S.-S. Chen, G.-Y. Li, and Z.-Z. Fu, "Safety criteria and limit resistance capacity of high earth-rock dams subjected to earthquakes," Chinese Journal of Geotechnology Engineering, vol. 35, pp. 59-65, 2013, in Chinese.

[25] J.-M. Zhao, X.-S. Liu, N. Chen et al., "Research on the maximum anti-seismic capability of high earth core rock-fill dam," Journal of Hydroelectric Engineering, vol. 28, pp. 98102, 2009, in Chinese.

[26] H.-J. Li, H. Zhong, and S.-C. Chi, Study on the Ultimate Aseismic Capacity of High Core Rock-Fill Dam, Geotechnical Special Publication No. 215, American Society of Civil Engineers, Reston, VA, USA, 2011. 